\title{
Maternity and Gynaecology services during COVID-19 crisis in Jordan: Challenges and solutions
}

\author{
Ibrahim Alsharaydeh ${ }^{1}$, Nail Obeidat ${ }^{2}$, Basil Obeidat ${ }^{2}$, Hasan Rawashdeh $^{2}$, and Noura \\ Saadeh $^{2}$ \\ ${ }^{1}$ NHS Highland \\ ${ }^{2}$ Affiliation not available
}

May 6, 2020

\section{Maternity and Gynaecology services during COVID-19 crisis in Jordan: Challenges and solu- tions}

Ibrahim Alsharaydeh ${ }^{\mathbf{1}}$, Hasan Rawashdeh ${ }^{2}$, Noura Saadeh $^{\mathbf{3}}$, Basil Obeidat ${ }^{4}$, Nail Obeidat $^{5}$

1 Assistant professor, consultant of Obstetrics \& Gynaecology. Jordan University of Science\& Technology

2 Assistant professor, consultant of Obstetrics \& Gynaecology, Jordan University of Science\& Technology

3 Speciality trainee, Obstetrics \& Gynaecology, King Abdullah University Hospital

4 Professor, consultant of Obstetrics \& Gynaecology, Jordan University of Science \& Technology

5 Professor, consultant \& Dean of faculty of medicine, Jordan University of Science \& Technology

COVID-19 pandemic has spread all over the world over the last few months. COVID-19 is an infectious condition and can spread, directly or indirectly, from one person to another. It involves the respiratory tract system and is caused by the newly discovered corona-virus, known previously as "2019 novel coronavirus", first identified in Wuhan, China, in December 2019. As of April 30. 2020, nearly 3,200,000 people across the globe have been infected with this virus with approximately over 230,000 confirmed deaths globally.[1][6]

Jordan is a Middle-Eastern country with approximately 10 million people, it is considered an upper-middleincome country, according to the World Bank. According to the Centre for Systems Science and Engineering (CSSE) at Johns Hopkins University[1] and world health Organization (WHO) website[2], the first case in Jordan was reported on March the $2^{\text {nd }}, 2020$. The total number of COVID-19 confirmed cases in Jordan as of April $30^{\text {th }}$, was 451 (Figure 1), with 8 deaths, 5 patients in critical condition, and 362 patients having recovered from the disease.

The Jordanian government made swift changes to address this crisis. Starting March $14^{\text {th }}$, 2020, Jordan suspended study in schools and universities, stopped gatherings in places of worship, closed its borders, and stopped all incoming and outgoing flights. This was later followed by an enforced complete lockdown (curfew). Five thousand Jordanians - who later flew into Jordan - were placed in quarantine in hotels in the Dead Sea region and in Amman for 14 days. The Ministry of Health assigned a few major hospitals in Jordan as referral centres for patients with COVID-19; one in the north, which is our hospital -King Abdullah University Hospital (KAUH)- and others in the middle and southern parts of the country.

Our institution, KAUH, is a tertiary canter with 683 beds, expandable to 800 beds during emergencies[3]. It is the teaching hospital affiliated with Jordan University of Science and Technology (JUST) School of Medicine, one of the leading medical schools in Jordan and the region[4]. KAUH is the only referral centre 
for COVID-19 cases in the north of Jordan, serving five big cities (a total of 3-4 million people). As of April the 30th, 2020, we treated about 103 patients diagnosed with COVID-19.

As the government announced the emergency state and later the lockdown, KAUH outpatient clinics were closed, and elective procedures and surgeries were rescheduled. The Obstetrics and Gynaecology department at King Abdullah University Hospital has made multiple adjustments to confront COVID-19 challenges. Challenges including; patients limited mobility as a result of curfew, limited number of medical and nursing staff and limited access to theatres, imaging services, blood banks and laboratory services. Therefore, we implemented changes at 4 levels: Patient care, Staff governance, Residency programmes and Medical student teaching programme.

\section{Patient care:}

After closing the routine antenatal and gynaecology clinics along with other speciality clinics, the hospital system kept some clinics open to refill prescriptions for patients with chronic diseases. During the lockdown, our aim was to continue providing care for all our patients (Table 1).

Patients with positive COVID-19:

We admitted 4 pregnant women who were confirmed positive for COVID-19. Patients were cared for in a COVID-19 special ward, the antenatal foetal and maternal observation remained normal. 2 of those patients required delivery by Caesarean section.

Patients with acute obstetrics and gynaecology complaints were referred by official authorities, media, and front desk personnel to visit the emergency department (ED), where an in-house team is available 24/7 to evaluate these patients. In general, inpatients were kept in the hospital for the lowest number of days possible without compromising their care to decrease their chance of getting hospital-acquired COVID-19.

Although antenatal clinics were deferred and rescheduled, the previously arranged induction of labour, and elective Cesarean section (CS) cases, were undertaken on time without delay.

Pregnant women who had urgent questions about their conditions were able to reach consultants and residents by telephone, as their phone numbers were available at the front desk and were given to patients and their families who contacted the hospital. The consultants and residents also used text messaging via social media to address some of the patients' issues. Patients whose problems were not solved over the phone were directed to the ED for further evaluation. Our midwifery team created a Facebook page to facilitate contact to all our registered pregnant women, the page was open for non-registered pregnant women as well. The page gained 3000 followers. Questions and quires, were addressed by both midwives and consultants.

We developed a triaging system based on COVID-19 risks. Risk factors covered the risk of exposure to COVID-19.

Pregnant cases with positive test were cared for in COVID-19 special suite, 2 of those patients required delivery by CS, CS was performed in the special suite, Spinal anaesthesia was used to reduce risk of staff exposure.

The entire staff took the necessary precautions and personal protective equipment (PPE), multiple swaps were taken from the amniotic fluid and the baby, all swaps were reported negative. The 2 newborns were separated from their mothers to reduce risk of acquiring infection. Both deliveries were uneventful and the babies were healthy. The two mothers recovered from COVID-19 and were discharged home.

A pathway colour-coded Red was designated for pregnant women who live in closed areas, had history of travel, had contact with virus-positive patients, or had mild respiratory symptoms; Those patients were admitted into isolation rooms, and cared for by a separate team, taking all the precautions and wearing the appropriate PPE.

A pathway colour-coded Green was designated for low risk maternity women who have been cared as routine. 
Although routine gynaecology clinics were deferred, we managed to maintain our care for cancer patients. Several measures were taken to reduce risk of infection; such as Laparoscopic procedures like total laparoscopic hysterectomy (TLH) converted to open approach, and shortening of the length of stay, with telephone follow up.

Table 1

\section{Staff Governance:}

As far as the work schedule for Maternity consultants and trainees, the emergency policy put forth by the hospital's administration - to minimize the exposure of health care providers to COVID-19 - was applied. Each of the 10-unit consultants covered the service for 1 day with no weekend block to reduce risk of viral exposure with high viral load.

We also modified the rota for residents who covered the in-house 24-hour calls; we reduced the resident numbers with less duties for trainees at high risk (eg. pregnant trainees). All consultants were available by phone to answer queries from both, patients, and in-hospital staff, and to help with reading CTGs.

We also reduced the number of midwives and nursing staff to the minimum number required to maintain the service safely.

\section{The academic program (trainees as well as consultants):}

Multiple adjustments were introduced; before the lockdown, we canceled the morning report to avoid the gathering of residents and consultants and to adhere to the social distancing rule. We used messaging applications to send learning materials to residents to study, and e-learning apps (like Zoom and Microsoft Teams) for consultants to participate in lectures and meetings.

\section{Medical student teaching:}

Has also been facilitated by technology. Our coordinators for the $5^{\text {th }}$ and $6^{\text {th }}$ year medical students uploaded course materials through an e-learning program, which is hosted by the official website of JUST. Clinical case discussions were conducted via Zoom for $5^{\text {th }}$ and $6^{\text {th }}$ year medical students. The process of distance learning is continuously monitored and assessed by the Centre for E-Learning and Open Educational Resources of J.U.S.T. The feedback has been excellent.

Use of telemedicine could be beneficial during this pandemic, as it facilitates care of patients through videoconsultation[5], while they are isolated at home. Some countries like the United States, the United Kingdom, and France have adopted and promoted the use of telemedicine during this pandemic[5]. In our hospital, work is ongoing to overcome technical and financial blockers hindering the full utilization of Telemedicine. We also adopted online and phone ordering and a home delivery system.

Finally, as the government plans to reduce restrictions and relax the level of lockdown, we prepared several measures to implement once routine clinics re-open. (Table 2)

Table 2

\section{Conclusion:}

COVID-19 caused an unprecedented health care global crisis with significant impact on Intensive care units, emergency departments and all other health care specialties. In KAUH we addressed our challenges, learn several lessons and implemented several measures on different levels to serve our patients, to ensure patients and staff safety and to facilitate trainees and medical students teaching.

Figure 1

Conflicts of interest: none declared

\section{Authors Contribution:}


Ibrahim Alsharaydeh: Main and corresponding author

Hasan Alrawashdeh: Analysis of data

Basil Obeidat: Editing manuscript

Noura Saadeh: Editing manuscript

Nail Obeidat: Analysis and editing manuscript

Ethical approval : Not required

Funding : No funding required

\section{Selected References:}

1. The Johns Hopkins Coronavirus Resource Centre. https://coronavirus.jhu.ed

2. World Health Organization(WHO) website. https://www.who.int

3. King Abdullah University Hospital website. https://www.kauh.jo

4. Jordan University Of Science and Technology. https://www.just.edu.jo

5. NHS Near Me- NHS Highland. https://nhshighland.scot.nhs.uk

6. Jordan Ministry of health Corona virus website. https://corona.moh.gov.jo/en

\section{Hosted file}

Figure.docx available at https://authorea.com/users/318414/articles/448309-maternity-andgynaecology-services-during-covid-19-crisis-in-jordan-challenges-and-solutions

\section{Hosted file}

Table1.docx available at https://authorea.com/users/318414/articles/448309-maternity-andgynaecology-services-during-covid-19-crisis-in-jordan-challenges-and-solutions

\section{Hosted file}

Table 2.docx available at https://authorea.com/users/318414/articles/448309-maternity-andgynaecology-services-during-covid-19-crisis-in-jordan-challenges-and-solutions 